\title{
Article \\ Family Business in the Digital Age: The State of the Art and the Impact of Change in the Estimate of Economic Value
}

\author{
Olga Ferraro * $\mathbb{D}$ and Elena Cristiano \\ Department of Business and Administration and Law, University of Calabria, \\ 87036 Arcavacata di Rende, CS, Italy; elena.cristiano@unical.it \\ * Correspondence: olga.ferraro@unical.it; Tel.: +39-09844922245
}

Citation: Ferraro, Olga, and Elena Cristiano. 2021. Family Business in the Digital Age: The State of the Art and the Impact of Change in the Estimate of Economic Value. Journal of Risk and Financial Management 14: 301. https://doi.org/10.3390/ jrfm14070301

Academic Editors:

Salvatore Ammirato, Stefan

Cristian Gherghina and David J. Edwards

Received: 10 May 2021

Accepted: 26 June 2021

Published: 2 July 2021

Publisher's Note: MDPI stays neutral with regard to jurisdictional claims in published maps and institutional affiliations.

Copyright: (c) 2021 by the authors. Licensee MDPI, Basel, Switzerland. This article is an open access article distributed under the terms and conditions of the Creative Commons Attribution (CC BY) license (https:// creativecommons.org/licenses/by/ $4.0 /)$

\begin{abstract}
Throughout the review of the most relevant literature on family businesses and business valuation, this work pursues a twofold purpose: to explore the possible evolutionary scenarios of family businesses in the era of digitalisation, highlighting their role and purpose; and to determine the valuation approaches that may be applied to them, also in light of the different role that intangible assets deriving from their digitalisation may assume. Therefore, after a description of the most relevant changes related to the digital transformation of the FB, the focus will be set on their valuation, paying special attention to the choice of the most appropriate methodology for "grasping" the aforementioned changes. Family businesses, in fact, due to their distinctive traits and the various estimation opportunities, require a dynamic business valuation process that has to be projected into the future and suitable for estimating those intangible assets that strongly characterise these types of companies, inasmuch as they are related to the implicit components that are strongly connected to the ownership and are a result of knowledge, strategic adaptability, and product innovation, and their possible impact on the risks and their expected flows. Thus, throughout a systematic literature review, the study provides, on the one hand, a clearer representation of the state of the art of the FB valuation in the digital age; on the other hand, it highlights the characteristics and peculiarities of "novel" FBs whose valuation needs to be conducted with due care.
\end{abstract}

Keywords: family business; digital era; digital transformation; business valuation

\section{Introduction}

Family businesses are an important resource for economic development and growth in many countries as they help to define the level of employment, demand models, portfolio choices, and educational schemes (Gersick et al. 1997; Ward 1987; Heck and Stafford 2001; Morck and Yeung 2003; Shanker and Astrachan 1996; Dyer 2003; Habbershon et al. 2003; Rogoff and Heck 2003; Zahra 2003; Bennedsen et al. 2007; Zahra et al. 2004).

The presence of some peculiar features helps to differentiate a family firm from other types of firms (Schillaci 1990; Davis 1983; Morris et al. 1997). These features can be traced back to: a family's bond with the firm; the differences between family members and external managers in terms of time horizon, pursued objectives, motivations, and interest in the success of the company; the strategic decision-making process; the organisational scheme and, in particular, the degree of centralisation and the intensity of the control activity; the relationship between family members and other stakeholders; the relationships within the family; the succession. Many authors believe that family businesses have an emotional dimension due to the bond between the family and their firm (Davis and Herrera 1998), putting emphasis on the fact that the presence of the family may influence the firm's performance and generate either positive or negative effects. Furthermore, technological evolution has revolutionised the habits and behaviours of the modern society.

Family businesses have responded to the challenge of digitalisation as, by the very nature of their business organisation, their decision-making processes are less time-consuming. 
The evidence for our statement was provided by the survey carried out by Deloitte in 2019 on a sample of 575 family businesses in 52 countries that are facing the digital transformation challenge in all business areas. This survey showed that FBs' long-term vision allows them to make decisions with a time frame not superior to three years, enabling a company to remain agile, flexible, and characterised with quick adaptability amidst change (Deloitte 2019; Conz 2020). According to the present research, the main advantage that differentiates FBs may be expressed with the concept of "rapidity". Family businesses can make prompt decisions and then put them into practice equally promptly. They tend to reduce paperwork, have more equitable positions on the board of directors, and can rely on the employees with a greater attachment to the company. Another important feature is the long-term objectives orientation that does not entail the risks of short-term approaches for mere personal benefit. The culture, history, and family values are definitely positive aspects that may help a family to survive throughout time and various periods of radical changes.

Like all businesses, family firms are often involved in situations that require an estimate of the economic value. However, due to their distinctive traits, accentuated in turn by the technological evolution implemented in recent years, family businesses require a "dynamic business valuation process which has to be projected into the future and suitable for estimating those intangible assets that strongly characterise these types of companies, inasmuch as related to the implicit components that are strongly connected to the ownership and are a result of knowledge, strategic adaptability, and product innovation, and their possible impact on the risks and their expected flows." (Dell'Atti 2007).

Particularly, the study emphasises how in FBs, along with "traditional" assets, one may find non-financial variables that allow an FB to create transgenerational values, e.g., for future generations, and that may be brought back to so-called "dynamic capabilities" (knowledge, business aptitude, experience and dedication of the owner and his/her family, product innovation).

Regardless of the estimation purpose, the chosen valuation method should take all these elements into account for a quantification of the FB value.

The objective of this work is twofold: firstly, to explore the possible evolutionary scenarios of family businesses in the era of digitalisation, highlighting their role and purpose; secondly, to determine the valuation approaches that may be applied to them, also in light of the different role that intangible assets deriving from their digitalisation may assume.

In order to achieve these goals, the authors conducted a review of the main literature on family businesses and their valuation approach.

Our contribution to the literature is twofold: on the one hand, a systematic literature review provides a clearer representation of the state of the art of FB valuation in the digital age; on the other hand, it highlights the characteristics and peculiarities of "novel" FBs and, therefore, the limits of the current valuation approaches for their estimation that should be taken into account for a correct assessment.

The work is structured as follows. Section 2 provides more clarity to the adopted methodology. Section 3 contains a literature review of the most relevant national and international studies on family businesses and evaluation issues. Section 4 explores the regulatory framework for the valuation of family businesses, while Section 5 features a description of the family business model in the digital age. The work concludes with some summary considerations on the topic, limitations, and prospects for further studies.

\section{Methodology}

In order to pursue the scope of the present work, the authors selected, first of all, the most relevant studies that had analysed FBs and their possible evolution scenarios in the age of digitalisation, highlighting the peculiarities and characteristics they ought to have. Drawing on this review, the most relevant studies that had been dedicated to the valuation of FBs were analysed in order to discover whether the present valuation methodologies are 
capable of grasping those non-financial variables that allow an FB to create transgenerational value, e.g., how to introduce these aspects in traditional valuation methods.

The reviewed articles were chosen according to the following principles: firstly, the most relevant articles to the purpose of this research were taken into consideration; secondly, we also reviewed the works quoted in the above-mentioned articles to expand the analysis of the literature and better understand the state of the art of the issue; thirdly, by the means of the Scopus database, more recent articles on the subject were also included. Last but not least, from the whole corpus of articles, those that did not meet the objectives of the present research were excluded, while preserving those that had carried out a form of a theoretical and/or empirical analysis of FBs and their role in the digital age or of the valuation methods used for FBs.

\section{Literature Review}

In this section, we analyse the literature from two perspectives: firstly, we focus on the family business by going back to the different definitions provided over time in national and international literature, showing the distinctive traits of the business model that characterise it. Secondly, we review the most relevant literature and practices, from both a national and international perspective, on the choice of the most appropriate methodologies for the valuation of FBs.

\subsection{Family Business Definitions \\ 3.1.1. Traditional Definitions}

The starting point for studying the dynamics of family businesses and all the features that differentiate them from other types of firms is to provide a specific and clear definition; however, there is no consensus among scholars on this issue. The first definitions consider an FB as a company in which the entire risk capital is held by a given family, while its members contribute with their work (Dell'Amore 1961), or a business in which at least two generations of the same family are involved and the family bonds have to influence business policies and the interests and objectives of the family (Donnelly 1964). These definitions, accepted in the past by the business administration doctrine, nowadays are considered very restricted and anachronistic as they do not consider neither the possibility of having several families who share control nor the presence of non-family members, such as professional managers, who assist family members involved in the business. Therefore, broader definitions have been developed and established in the literature. A common position shared by many scholars is the one that considers an FB as a company controlled by the members of a single family (Barry 1975) or the one in which an individual or multiple members of a single family have a controlling shareholding (Barnes and Hershon 1976). Another definition of FB is a profit-oriented business that can take the form of a sole proprietorship or a company in which the family, where the property is also held by external parties, has to be involved in management (Alcorn 1982). Moreover, a company is considered to be an FB if the members of a family have legal control over its ownership (Lansberg 1988). As it can be observed, the common feature of these definitions is the ownership factor, regardless of the involvement of family members in management activities. Different criticisms of this approach have been raised by some scholars who define a family business as the one in which the number of participating subjects is limited and the ownership and decision-making process are dominated by a group of subjects tied by emotional and parental relationships, thus highlighting the empathic involvement of the family in the business (Carsrud 1994) or the close relation between the two institutions, i.e., the family and the business (Davis 1983; Handler 1994; Tagiuri and Davis 1996; Ferrero 1989). These works propose three mandatory conditions to consider a firm as an FB, namely the ownership held by one or more families, the consideration of the business as a part of the family itself, and the involvement of family members-other than its founder-in management. Other definitions focus on the dominant influence of the family, not only which concerns control but also the governance of the firm (Dyer 1986; Chua et al. 1999; 
Di Stefano 1996; Dell'Atti 2007). Other scholars (Westhead and Cowling 1998) add to the definition the family's desire to continue to maintain control and ownership of the company throughout the generational renewal. Schillaci (1990) proposes to merge the two aforementioned criteria, defining an FB as "an entrepreneurial activity that can be intimately identified with a family or a group of families, for one or more generations. The influence of the family is legitimised by the partial or total ownership of the risk capital and it is also exerted through the participation of some of its members in the management". It is clear that the role of a family can also involve absolute control, i.e., on ownership, governance, and management, but most frequently it is a dominant role that affects the organisation and management of the company. In relation to this aspect, Corbetta and Dematté (1993) consider FBs as those companies in which "one or more family units tied by close bonds of kinship or affinity make financial capital, personal guarantees or collaterals available to the company at full risk or limited risk. We mean family business when one or a few families tied by bonds of kinship, affinity or solid alliances hold shares of risk capital in a sufficient quantity to ensure the control of a business". On this basis, family businesses are those enterprises in which the control is held by one or more families by virtue of the total (closed family ownership) or prevailing (open family ownership) ownership of the risk capital; corporate governance is mainly exerted by one or more family members with a total and direct control on entrepreneurship, which can also be associated with the total or partial control of management functions. With particular regard to corporate governance profiles, two types of family businesses can be placed at the extremes, i.e., FBs in which all entrepreneurial and management functions are consolidated in a single individual (business owner) or in a small number of subjects belonging to the family; and FBs in which entrepreneurial functions, but above all the management ones, are assigned also to non-family individuals. Generally, the first type includes those companies that bear a very high degree of centralisation of ownership among family members (in many cases, even an absolute control), from which derives the possibility to assign this category to small-sized companies. On the contrary, the second type commonly identifies those companies that are open to the participation in risk capital by non-family subjects. In these companies, also thanks to the consequent greater financial resources, it is easier to implement the managerial models associated with medium-large-sized companies. Having said that, we cannot exclude the possibility that small family businesses may include subjects unrelated to the family, who can also participate in the entrepreneurial activities and to whom managerial functions are totally delegated, but this case is certainly less frequent. Beyond these differences, the element that characterises FBs and differentiates them from other business models is the coexistence of three interdependent systems: the family, the company, and the entrepreneur's assets (Gersick et al. 1997; Le-Breton-Miller et al. 2004; Ward 1987).

\subsubsection{Evolution in Definition}

As far as the definitions and classifications reported above are concerned, it emerges that the institutional overlap between family and business, together with the decisive influence of the owner and his/her family members on the life of the company, occurs in particular in small family businesses that adopt an entrepreneurial management model. In these companies, which are largely based on pure entrepreneurial models (Marchini 2000), the risk that business goals end up subordinated to the family ones appears to be higher. Moreover, the problem of preserving the value of the business over time arises, as the wealth of knowledge and skills that should be transferred belongs mainly to the entrepreneur itself (Daspit et al. 2021). With this in mind, it is worth remembering that an enterprise, defined as an entity intended to persist (Zappa 1957), has its own institutional purpose, namely that of creating value in terms of production and equitable distribution of wealth in a durable way. Therefore, the company has to operate in conditions of efficiency, effectiveness, and cost-effectiveness, i.e., it has to be able to create wealth over time by adopting rational management behaviours and granting the appropriate remuneration 
of all the production factors in relation to theirs (Onida 1971; Cassandro 1980; Di Cagno et al. 2011; Swab et al. 2020). Following the changes in markets and economic scenarios, the rigid boundary between these two aspects has gradually evolved until it reached a broader definition which, considering both criteria, allows for including a larger number of organisations into the FB category. This approach, by making no reference to the size of the company, allows for including in the sample not only small and medium-sized companies, i.e., the ones traditionally associated with family businesses, but also large companies such as multinational corporations. Furthermore, the bond between a family and the company clearly demonstrates the interdependence of these two institutions, also in sharing the values of the former by the latter, and the role that family members, not only in relation to the work provided internally and necessary for its qualification as a family business, play in the processes of generational shift. Where the role of economic governance and management is concerned, first-generation family businesses can be differentiated from second-generation ones. In accordance with this classification, in a first-generation business, the aforementioned roles are played exclusively by the members of the family who initiated them and not by the following generations (Conz 2020). Hence the distinction of FBs into three defining categories. The first defines FBs as those businesses in which a family holds strategic control of the company with the involvement of one or more family members in the BoD or as employees. The second, an intermediate category, includes the FBs in which the founder or the successive owners aim to hand down the company to successive generations while playing an active role in the management of the company. Finally, the third category includes FBs in which different members of the family, belonging to different generations, have managerial responsibilities in the company, working in close every-day contact (Astrachan and Shanker 2003). The academic debates on the subject, by putting emphasis on the behaviour of FBs and its impact on resource management, share the definition of FB based on the real essence of the family business and on the involvement of the family in the company (Sharma et al. 2014). In this perspective, an FB is a business that is controlled and/or managed while pursuing the vision of a dominant coalition formed by the members of a family or a small number of families in a way that ensures the potential sustainability of the business through the transfer to future generations (Chua et al. 1999). In Italy, the presence of family-owned businesses amounts to $44 \%$ of the total (Corbetta et al. 2020). The survey conducted on a sample of 17,984 companies with a turnover greater than EUR 20 million showed an incidence of $65.6 \%$ of family businesses, divided into small (69.1\%) and medium-large (61.6\%), and with a considerable presence of family leaders (73.2\%). The manufacturing industry is the one with the greatest presence of family businesses; moreover, these firms boast a higher growth rate than non-family businesses in all industries. The perceptions that family businesses invest less in marketing and innovation than non-family businesses and that they are reluctant to change, due to their tendency to preserve their own corporate culture linked to tradition (Blombäck and Craig 2014; Rondi et al. 2019), are also widespread in other countries in Europe and all over the world. However, this can be considered a static perception that does not take into account the fact that the distinctive features of FBs (such as the family culture, the long-term vision, the aspirations of family members, the generational transition, and the entrepreneurial vision of the leader and his successors) are critical factors of success that may lead to a competitive advantage. The so-called familiness allows for developing trust among consumers and all the stakeholders who deal with FBs, providing the elements from which the evaluation of company performances can be started.

\subsection{Valuation Approaches of Family Businesses}

For the estimation of companies' economic value, the business administration doctrine has developed various methodologies over time (Corbella et al. 2020), without, however, reaching a consensus on a dominant method (Demirakos et al. 2004). In fact, the choice of the method depends on various factors such as the evaluation framework, the object under 
evaluation, and the industry in which it operates. All of these elements may impact not only on the choice of the method but also on its potential applications.

In addition to understanding which method is the most suitable to understand the business phenomenon in its complexity, an expert has to verify if the information provided and required by the chosen method is reliable and applicable (Marcello and Pozzoli 2019).

The aforesaid is particularly important if the object of the estimate is an FB: each method that respects the requirements of rationality and uses supportable information is generally acceptable, and therefore the choice has to be guided by the specific circumstances of the case (Tiscini 2001).

The valuation of a family business certainly requires different theoretical approaches from those normally suggested and applied in ordinary business valuation (Viganò 2005).

Despite the presence of numerous theoretical and empirical studies on company valuation, the issue of family business valuation has been scarcely discussed or either associated with the valuation issues related to SMEs. However, there is a number of studies-though limited-that have examined the applicability of traditional valuation methods, with appropriate adjustments, to estimate the economic value of FBs.

\subsubsection{National Context}

Tiscini (2001), in his work on family-owned SMEs, linked the choice of the valuation method to the company prospects and the current stage of the company in its life cycle. In particular, the author suggested the use of methods based on quantities-flows, such as the DCF or income-based methods with discounting of individual future income, when it is not possible to detect any regularity in trends. Meanwhile, in stationary and stable trends, it is appropriate to resort to methods that employ average-normal result projections, such as the pure income method or the mixed equity/income-based method with an independent estimate of goodwill (with a stable level of surpluses). Furthermore, if the future trend of an FB is characterised by clearly identifiable results and a steady growth, it may be appropriate-with due caution and prudence-to adopt perpetual growth models, such as the Gordon model. The adoption of this model is particularly recommended in the expansion phases of a family business as it takes into account its growth prospects in the medium term.

For all the situations characterised by highly unpredictable scenarios that preclude reliable projections of results in the medium term, the author suggested the application of more conservative valuation methods, such as the mixed method with independent estimate of goodwill and the pure income-based method.

Regarding the use of empirical methods, Tiscini (2001) pointed out how identifying samples of companies (or transactions) that are truly comparable among each other is fairly difficult, and this is even more the case for FBs as the economic combinations and management logics are very diversified. For these reasons, when the pricings of comparable companies are used for the valuation of FBs, the author specifies the errors that need to be avoided (Tiscini 2001).

As far as the approach to comparable transactions is concerned, the issues are related to the retrieval and organisation of data on comparable transactions, the verification that the transactions have been made under free negotiation conditions, the clauses included in the negotiations that may have an impact on the value, and finally the accounting data that should be effectively and homogeneously reclassified according to the uniformity of the object and the circumstances of the valuation.

According to the author, the aforementioned limits are the reasons behind the popular choice-when it comes to the estimation of family businesses through empirical methodsof the rules of thumb not based on methodologically correct statistical sampling but simply on "a collective opinion spread in a specific sector or in similar sectors, indicating the purchase and selling potential prices of a company" (Guatri and Bini 2005). While acknowledging the usefulness of this approach for the valuation of small and mediumsized family businesses, Tiscini (2001) drew attention to a series of precautions to be taken 
into account (Desmond 1993) while pointing out the need to not consider it as a complete method for evaluating companies but rather as a control method for preliminary estimates or in case the accounting data are unreliable.

In his work, Viganò (2005) put emphasis on the different limitations typical of traditional methods when applied to family businesses. The first group of limits is strictly connected to the reliability of the financial data and, therefore, to the adoption of methods based on quantities-flows. The balance sheets of family businesses are generally prepared by adopting accounting rules of a legal-fiscal nature, while the analytical valuation methods require financial data of a technical-economic nature. Furthermore, financial data are often contaminated by assets and income-related elements that confuse a family's economic dynamics with those of the company: income may be easily conditioned by the amount of "family expenses" that appear fictitiously among company costs (only for tax purposes). In the same way, the mixture between the assets of the company and those of the family happens frequently. The correction of income and cash flows through a normalisation process is obviously possible, but the author underlined its greater complexity that adds indeterminacy to the calculation of quantities that are already complex by their nature.

As regards the equity-based methods, Viganò (2005) considered them insufficient to represent on their own the value of the company for two reasons. The first one is closely related to what has already been said on the unreliability of balance sheets. The second one concerns the role of intangible assets, whose appreciation in FBs appears even more difficult to ascertain as a static element.

With regard to the applicability of the multiples approach, Viganò considered it unsuitable for FBs when applied in Italy or mainland Europe. It is not easy to find a sample of comparable listed companies (or similar transactions), and this difficulty tends to grow when the object of the estimate is an unlisted family business.

Ultimately, Viganò favoured the rules of thumb which, whilst some consider them among the bluntest and indirect criteria for evaluating a company, are perhaps the most appropriate to obtain general values with an acceptable degree of significance in the field of family businesses (Viganò 2005). The use of these criteria seems further supported by the simplicity of calculation and the immediacy of the result, helping to spread the awareness on value, especially for small companies (Mussolino et al. 2005).

Dell'Atti (2007), after presenting the different methods that can be used to evaluate companies (FB included), pointed out how the existence of some typical factors of the Italian economic reality (such as a scarce interest in financial markets and limited available resources, combined with the typical traits of FB and their uncertain economic and financial situation) results in a scarce use of financial or income-based methods. In line with what has already been underlined by Viganò (2005), Dell'Atti considered financial statementsthe instrument on which these methods rely-quite partial and incomplete to express the value of an FB characterised by unexpressed components and strongly connected with the ownership matrix.

According to the author, equity-based and mixed methods, by contrast, have relatively high levels of rationality, generality, and objectivity and relatively low levels of sensitivityvolatility. In particular, the method relying on the independent estimate of goodwill to "stratify the value" while highlighting all the components (static and dynamic) and differentiating the value between the one associated with the history of the company and the one linked to its prospects is suitable for the valuation of FBs. In this regard, Dell'Atti (2007) suggested splitting the formula of the mixed method with independent estimation into two addenda: a management component $(P N R+(R-P N R \times i)$ an $\neg \mathrm{i})$ and a family component (SA $+\mathrm{R}^{\prime}$ an' $\left.\neg \mathrm{i}^{\prime \prime}\right)$. The latter stands for the surplus assets deriving from the activity of the family component to provide expression to the family component.

Obviously, the same conclusions may be reached for the formulas underlying the other valuation methods, whose adoption can be a useful term of comparison. Finally, in line with other studies, Dell'Atti (2007) considered the methods based on rules of thumb to be particularly suitable for the category of FBs. 
Liberatore (2012) — when referring to the application of mixed methods and the complex equity method-did not propose a "modified" application formula, pointing out that the magnitude of influence that a family exerts on business management can be analysed through the contribution of commitment and skills and the transfer of tangible assets. For the latter, the value quantification is not particularly problematic, provided that there is a reference market from which a realisable value can be deduced. When a price and a use value are available, it is also possible to deduce if the charges requested by the family to the company are adequate when the use of assets is granted.

In contrast, for intangible assets without an active market, such as the commitment and skills that family members invest in the company, the estimate is somewhat problematic. First of all, it is necessary to differentiate between intangible components intrinsic to the presence of family members (business aptitude, experience, knowledge, and dedication of the owner and his/her family) and assets that can be identified and separated from the family (brand, distribution chain, customer portfolio, production and commercial know-how, and patents): the former need to be included in the value of the goodwill while they will be subject to an independent evaluation, according to the criteria identified by the doctrine (Picone et al. 2021).

Goodwill can be determined directly by discounting the surpluses that the company is able to generate or indirectly by determining the economic value of the company and subtracting the PNR and the identifiable intangible assets.

Finally, Liberatore pointed out that, in calculating the extra income, it is crucial to neutralise the effects deriving from the relationship between the company and the family: for instance, the remuneration of family members needs to be parametrised to the standards envisaged for managers of the same level and competence, while the use of family assets by the company will be standardised at market levels (and vice versa).

While analysing the regulatory and doctrinal framework regarding the valuation of small businesses, Cecchetto (2019) pointed out, among other things, how the adoption of empirical methods for the estimation of an FB can be a solution in exceptional situations (e.g., due to lack of data or peculiarities of a given industry) and in contexts of non-legal valuations in which the public function would force to refuse the appointment, since it is impossible to have an adequate information base for the task. Moreover, while hypothesizing some "simplifications" of the valuation process for SMEs, the author suggested departing from the formulation of the mixed method contained in the Italian Valuation Principles (hereinafter, PIV) by calculating goodwill as the differential between the average-normal profitability and the return on capital in a synthetic form, due to the absence of typical planning instruments and given the expert's will to not interfere with management in the formation of prospective flows. Similarly, the traditional formulation of financial methods-which require punctual financial flows - may be abandoned in favour of a simplified financial method, based on an average-normal cash flow.

\subsubsection{International Context}

International studies on the choice of the most suitable approach for estimating family businesses are also scarce.

Wright (1995) emphasized the fact that value is subjective and the valuation of a FB is never accurate. In particular, the author stated the importance of historical and prospective economic-financial information and how, when correctly weighted, these are essential to obtain a correct fair value at the basis of the valuation process. However, he also pointed out the limits of financial statements in the representation of the intangible elements that play a central role in FBs. All of these perspectives need to be taken into consideration while determining the value of an FB. Therefore, the author concluded by stating that, for an FB's valuation, it would be appropriate to combine several approaches and obtain a range of values from where the final overall value can be drawn.

For Hitchner (2012), the valuation of an FB's shareholdings requires the same approaches used in the valuation of any other company. The degree of applicability depends 
on the valuer's judgement, combined with the facts and circumstances of the case. The income-based method, for example, has some limits in estimating the shareholdings of FBs, as in this case there may be activities that do not generate a continuous income flow. Furthermore, some duplications of value may arise when cost- or market-based approaches are adopted for the valuation of individual assets in the financial statements: the application of the income-based method would lead to their duplication. Such limits may lead to the use of the equity- or market-based methods.

Hasso and Duncan (2013), through a review of the most relevant literature on the valuation of FBs, highlighted that accounting data may not be helpful for grasping the reality underlying these types of companies, especially for three main aspects: assets, returns, and risk. According to the authors, these shortcomings make the most popular valuation methods for estimating the value of FBs inadequate. In fact, both asset values and income/capital flows are underestimated, with the consequent underestimation of companies with respect to their actual intrinsic value. Furthermore, the estimation of the cost of risk capital in FBs is more complex due to the factors that constitute risk capital and debt capital. The authors, therefore, suggest the development of specific valuation models for FBs or the modification of the existing ones by taking into account the limits of the accounting data identified in their study.

Ballwieser (2017) asserted the dominance of the DCF and multiples in the value estimation of FBs, underlining the validity of the DCF for a correct estimate of the value of these particular companies, while acknowledging some limitations related to the dividend and financing policies that may impact on cash flow forecasts. More difficulties in applying the DCF and multiples methods could instead occur in the case of small and medium-sized FBs, given the limitations in forecasting cash flows and prices.

\subsubsection{Empirical Studies on the Valuation of Family Businesses}

Research on the valuation of FBs through the study of practice is poorly developed. Most of the empirical studies on estimating the economic value of FBs are based on the multiples approach, neglecting the other valuation methods. Such a narrow base represents a significant gap in the literature and stands as a limitation of the published studies. In fact, each valuation method can lead to different valuations. Focusing on just one method may lead to misleading conclusions in terms of company value (Hasso and Duncan 2013).

Granata and Chirico (2010) compared the valuation of family businesses with nonfamily businesses during the pricing for an acquisition. The aim was to understand if there would be any difference in value between the two "types" of companies when they are the object of an acquisition. The authors pointed out the unique and distinctive traits of family businesses with respect to non-family ones, including the fact that family members are also active members of the business and influence its economic value. In particular, the study showed that although family businesses are recognised as performing better than non-family ones, buyers tend to consider the former as unprofessional and inefficient organisations in which decision-making processes are driven by emotions rather than by economic rationality. For this reason, buyers are willing to pay less (i.e., at a discounted price) for an FB with respect to a non-family business. In empirical research, the estimate of the acquisition price takes place through the application of the multiples approach, in particular the EBITDA multiple, using the approach based on comparable companies.

A joint analysis of the studies by Viganò (2005) and Mussolino (2008) highlighted how the results deriving from the research, in relation to the different valuation methods adopted, show a clear prevalence towards the use of equity-based (53.95\%) and mixed $(25.17 \%)$ approaches. These are followed by the approaches based on income and financial flows $(10.79 \%$ and $9.45 \%$, respectively) used by about $20 \%$ of the group's business owners who have implemented the valuation processes at least once. Finally, approaches based on multiples and market value are applied only in over $5 \%$ of cases. It is important to highlight that in one-fifth of the cases, corrections were applied to the traditional valuation methodologies in order to take into account the specific traits of the company, such as 
size and family influence, while no corrections were applied to the control premium, the minority discount, or the illiquidity of the shares.

A comparison of 152 companies based in Spain showed a substantial difference in the applied valuation methodologies (Mussolino 2008). In fact, while the mixed method was confirmed as the most popular (27.87\%), the methods based on financial flows, market value, and multiples are more frequently applied ( $24.59 \%$ and $26.23 \%$, respectively) in Spain compared to Italy. These are followed by the equity-based method $(19.67 \%)$, while the income-based approach is almost never taken into consideration (1.64\%).

\section{Valuation Approaches According to International Valuation Principles}

As is common knowledge, the growing need to initiate organised and homogenous valuation processes for the estimate of the economic value of the companies on different occasions has over time shown the necessity of implementing guidelines, reference principles, and rules. These were developed and distributed in various countries by recognised valuation entities. Therefore, the study of family business evaluation cannot ignore the perspective of the above-mentioned principles and guidelines.

An overview of the main national and international standard setters for valuation, in addition to the lack of a specific method for family businesses, highlighted the lack of the valuation of minor enterprises (SMEs) in general, probably deriving from the assumption that these two types of enterprises have similar traits and peculiarities, together with the common idea that a standard (one size fits all) and a valuation process (valuation is valuation) are always valid (Marcello and Pozzoli 2019).

The first international body that has dealt with the issue of SME valuation in a specific document is the Fédération des Experts Comptables Européens (FEE 2001) which in 2001 published a guide describing the valuation principles to be applied to support the transfer of an SME. In particular, the document explores in detail the methods based on quantitiesflows and the method based on multiples, adapting them to the estimate of SMEs. For the former, the guide provides a series of recommendations for the future estimation and the possible normalisation of flows. For which concerns multiples, a simplification is recommended with respect to the price variable for their use as a control method.

Later on in 2005, the Asociación Española de Contabilidad y Administración de empresas (Ramírez et al. 2005) published a document in which the DCF and equity-based methods for SMEs are extensively illustrated, along with several practical examples that serve as a guide for a concrete application. In the document, each of the components of value is addressed separately with a specific calculation methodology. In particular, with reference to the discount rate, some specific procedures are proposed for its estimation in order to balance both the risk and the lack of cash and control associated with SMEs.

In the Mission d'évaluation (Ordre Des Experts-Comptables 2016) compiled in France and containing techniques expressly dedicated to SMEs, there is a brief description of a fasttrack methodology for estimating goodwill for small businesses by the use of coefficients (barèmes): the method, largely based on the rules of thumb and widely applied in courts, provides the calculation of the company value by multiplying the average turnover (chiffre $d^{\prime}$ affaires moyen) of the last three years for a coefficient that varies according to the type of activity. Taking into consideration the margins, the method makes it possible to refine this first valuation of an SME: the ratio between income (normalised to consider implicit costs) and turnover captures the peculiarities of each business in order to evaluate an increase or decrease in the used coefficient (Cecchetto 2019; Amaduzzi et al. 2016).

In the guide L'évaluation financière expliquée: principes et démarches (CNCC 2016), while identifying the preferred estimation approach in the DCF, it is noted that the absence of the typical planning instruments entails the preference for the use of mixed or, more often, income-based equity methods. Furthermore, Annex 4 of the guide provides a simplified method for determining the discount rate: starting from the risk-free rate, the cost of capital is quantified by considering market risk, risk due to the lack of liquid assets, sectoral risk, and specific business risk. 
Finally, French professionals can benefit from an additional operational tool for the estimation of SMEs, i.e., the document Taux d'actualisation et multiples de valorisation (CCEF 2018) in which the discount rates used in the application of traditional absolute methods and the multiples for quantifying the value on the basis of the relative methods are provided every six months. The valuation is carried out by CCEF in accordance with the reference industry and the size of the company, in order to take into due consideration the risk related to the illiquidity of the investment in unlisted companies and the risk associated with the size of the company.

In Germany, the IDW S1 "Principles for the performance of business valuation" pays specific attention to the valuation of companies in particular situations, including SMEs. According to the German principles, in order to evaluate small companies, it is necessary to pay special attention to various aspects, such as the definition and identification of the company being valued, the remuneration of the management, and the reliability of information sources. Furthermore, the principles underline how the reference to "simplified prices" is frequently made with respect to SMEs by using multiples of profit and multiples related to sales or product quantities deriving from transactions of comparable companies. Therefore, simplified pricing methods can serve as a basis for assessing the reasonableness and plausibility of the results drawn from the financial method, considered as the most relevant method. In addition, IDW (2014) published a set of practical guidelines for SMEs that examine more specifically the potential impact of company size on valuations.

The Italian Valuation Principles (PIV) issued by the Organismo Italiano di Valutazione (OIV) are not specifically aimed at SMEs; however, the presence of the principle of proportionality and the possible simplification in the process may lead to a concrete application of the principles to SMEs (Cecchetto 2019). In particular, the PIV principles state that the contents, amplitude and level of detail of the valuation process stages are nonetheless conditioned by the available information (e.g., a small size can affect the extent of the available information, reduce comparability, etc. in the valuation of a company). Generally, when internal information is reduced, external information should be more developed in parallel (PIV I.4.3, point 5). In paragraph III.2.4, regarding the valuation of companies of different sizes, point c states that the size factor, which may be influenced by the availability of formalised plans and adequate management or organisational structures, has to be considered by an expert in order to make and justify any valuation choices.

Finally, one has to mention the document recently prepared by the Italian Working Group of the National Council of Chartered Accountants and Accounting Experts and the National Foundation of Chartered Accountants on the generational transitions of FBs (CNDCE-FNC 2020). The aim of this document consists in providing an overview of the issue to support professionals in identifying the tools that would allow them to adequately protect and preserve family assets in the course of transactions. As regards the valuation profiles, the document describes the issues associated with the application of multiples, due both to the complexity in identifying an adequate number of comparable companies and to the fact that the process is not intended to measure the value of a company on the basis of evidence inferable from the market. The document suggests adopting other methodologies but with "necessary precautions", taking into account the specificity of the object of estimation. It is important to evaluate the company without any conditioning imposed by a family: specifically, the evaluations based on the projection of economic or financial flows should consider, albeit in a stand-alone logic, the operating conditions existing at the date of valuation, deprived of any element that may influence the measurement of the company's fundamental value (e.g., abnormal costs of the administrative body caused by the presence of all members of the family unit). It is also salient to differentiate surplus assets from the fixed assets related to the business activity (CNDCE-FNC 2020, p. 35).

Once the analysis of the aforementioned documents is completed, it is emphasised that there are currently no specific methods for family businesses. Therefore, in the absence of a specific method, it would be appropriate to consider the references to SMEs as a guideline for estimating family businesses, provided that their specific peculiarities and 
characteristics are duly taken into consideration in setting up the valuation system as a whole.

\section{The Family Business in the Digital Age}

Digital technologies through the integration of people, companies, and assets contribute to the fast pace of these changes. As is well known, one of the distinctive traits of family businesses is their resistance to change, which is summarised in the tendency towards continuity of long-term management of the company over several generations. Many family businesses, however, while maintaining the characteristic of upholding business continuity, are adapting to the digital world in a very short time, seeing an opportunity for innovation and change capable of safeguarding their existence in this new concept of doing business. With this in mind, the adaptation of a business for meeting the challenges of the digital age is an important responsibility for the next generation of family business leaders. An erroneous concept about digital transformation is to believe that it consists only in the digitalisation of the current management method and of interactions with third parties. The opportunities for innovation are far greater. Taking into consideration, for example, the opportunities for digital interactions with the customer, it becomes obvious that it is not merely about digitising the existing touchpoints but mainly about reinventing new levels and methods of interaction to get closer to the customer. Similarly, digital transformation consists in moving from a traditional organisation that executes digital projects to a digital organisation with an integrated strategy that places digital technology at the very heart of its business (Ammirato et al. 2019).

In support of this new trend observed in FBs, it is interesting to look at the results of a recent survey (Deloitte 2020) conducted on a sample of 575 family businesses in 52 countries, where it was observed that businesses had already implemented (25\%) or recently implemented (35\%) or were planning (40\%) a digital transformation strategy. In this context, it is significant that only $11 \%$ of companies were founded less than 20 years ago; almost 36\% were founded between 20 and 49 years ago, 37\% between 50 and 100 years ago, and $15 \%$ over a century ago.

Such a survey shows that digital transformation takes place also in family businesses. It should be emphasised that despite FBs' peculiarities, when compared to non-FBs, digitalisation is seen as an important growth opportunity, especially among new generations. The effects of such a transformation will be seen after the next 5 years, and this is why close monitoring of its progress is needed to conduct a future confrontation between digital transformation in FBs and non-FBs.

Most of the family business leaders surveyed (53\%) belong to the second generation that has reached the top of the family business, $29 \%$ to the third, and $18 \%$ to the fourth or successive generations.

Therefore, this change fits well in the context of a generational renewal destined to bring new life to traditional FBs, although resistance to change may occur among other family members who do not share the same awareness about opportunities with the leaders of family businesses of the present and future generations. In the context of FBs, digitalisation is primarily intended as an opportunity for process improvement, as it is, above all, considered an operational improvement tool, without fully taking into account potential applications. This is a typical situation that, in most cases, requires a gradual introduction of digital technologies in FBs that will be followed by their application in other areas, such as innovation and development of new models and business talents, often through the use of digital platforms. Future leaders of family businesses are certainly more aware of the impact of digitalisation than other family members working in the company who, in turn, are perceived as more aware than family members who are not active in the company. In an FB, the coexistence of different generations, in terms of age and culture, undoubtedly complicates the process of introducing smart technologies within these companies. In many cases, the younger generations, often about to take over the company from the older ones, have to engage in educating other family members 
about the value of digital technology. As a matter of fact, it is precisely due to the culture rooted in this particular business model that it may become necessary to invest more time and resources in discovering the uses and implications of digital technologies than in non-family businesses. In order to benefit more from digitalisation, family business leaders should promote the integration of different technologies and information systems into their companies. Family businesses can take advantage of their traditional focus on long-term planning to prepare the business for the "future needs" of digital transformation and adapt the entire organisation-not just the business, but also family members—to the digital future.

Family businesses are complex organisations, and motivating factors at the company level and the opinions of family members may not be aligned. This may result in a denial or underestimation of new opportunities. However, family businesses are known for their flexibility when facing a change thanks to their long-term perspective and the desire to hand down the business to the next generation. Family businesses are able to react promptly and firmly to the evolution of market forces and, in general, have adequate financial resources as they are not particularly dependent on external financing. Therefore, the cost of adapting their structure to the implementation of new technologies should not be an impediment to change. However, it is also well known that FBs have a reputation for risk aversion which, in some cases, could slow down the process of change, and this is a typical trait of the "prudent and constant" approach of many family businesses. Nevertheless, whereas a prudent approach can be perfectly reconciled with family culture, on the other hand, family businesses have to balance prudence and conservative attitude with the need to avoid being left behind. For a successful future, companies need a digital agenda: the ownership of digital assets may not be necessary, but the ability to leverage the opportunities offered by digital assets owned by third parties will be. Companies will also have to develop new ways to create relationships and interact with third parties. New competitors and start-ups, as well as competitors already well-grounded in the market, are taking advantage of a series of opportunities offered by an evolving context. Family businesses that will be able to develop their culture and business practices to benefit from these opportunities would gain a competitive advantage. Digitalisation is a process that impacts on business, organisation, and production; therefore, a substantial awareness of the issues and tools offered by digital innovation is essential. Therefore, digitalisation cannot be limited to a mere set up of a website but has to consist of a much longer and more radical process that begins with the transformation of the core business processes. This is achieved with the implementation of new technologies, such as artificial intelligence. As it is well known, digital transformation encompasses a wide range of digital technologies, scopes of application, necessary skills (regulatory and IT), and different organisational and economic impacts (Pasini and Perego 2016). In order to achieve all of these elements, it is also necessary to completely reassess the business model of a company by questioning the value of the brand, the core skills, and the decisions about what to invest or divest. Therefore, it is possible to redefine the business model by the evolution of the existing organisation (Notarnicola and Carvelli 2017). To succeed in the digitalisation process, the continuous support from business leaders is salient and decisive, along with strategic partnerships that provide resources and skills for achieving the set objectives. Moreover, it is also important to change the organisational structure as a whole, not only by introducing, for example, an e-commerce to sell products online but also by reforming the core activities of the organisation itself. In order to obtain this goal, a cultural change towards the so-called digital culture is essential (Hemerling et al. 2018). Digital transformation offers faster and more accessible sources of information to consumers and stakeholders, allowing them to become more rational and aware in their choices, being also more active and involved in the dissemination of information on digital platforms. In this scenario, FBs will be able to exploit these channels to convey their family identity and thus improve their performance, hence the importance of investing in digitalisation as a lever for the renewal of a family brand, a concept that has become even more important in the post-modern reality, characterised by globalisation 
and international challenges and by a change in the purchasing behaviour of consumers who have become more online-oriented. When compared with non-FBs, especially in the case of well-established businesses, FBs can be favoured in terms of communication, as they are able to present a heritage of stories, places, and traditions that are perceived as a quality guarantee by consumers and other stakeholders. Wide-ranging investments in FB digitalisation offer several advantages in terms of performance improvement. When confronting the digital revolution, FBs are favoured by their general reputation and by the network of social, local, and family ties which now constitute a capital generated over time and allow them to maintain and develop strategic partnerships and collaborations with external stakeholders. Undoubtedly, the path to digitalisation is not a short one and has to be carefully planned. However, we cannot overlook the difficulties that an FB, especially if small-medium-sized, could encounter in terms of financial resources and internally available skills for a timely digital transformation. Technological solutions are evolving rapidly, requiring a fast-paced and constant cultural update with respect to digital innovations. Therefore, due to their peculiarities, FBs have to make a greater effort than non-family businesses as they are required to invest in transversal skills and to rely on experts in data processing and measurement and to quantify the effects on corporate performance of the investments planned for digitalisation.

\section{Conclusions, Limitations, and Recommendations}

The present study, throughout a review of the main literature on FBs and on company valuation, aimed at, on the one hand, exploring the possible evolutionary scenarios of family businesses in the era of digitalisation, highlighting their role and purpose, and on the other hand, determining the valuation approaches that may be applied to them, also in light of the different role that intangible assets deriving from their digitalisation may assume.

In this paper, we highlighted how family businesses have undergone a change in strategies, business models, organisational models, and leadership as a result of digital transformation, though without neglecting the history, culture, and traditions well consolidated into the family.

These changes need to be appropriately "quantified" on various internal and/or external situations that require an evaluation process. The theoretical and empirical literature on the choice of the most suitable approach to estimate the value of family firms is limited; however, all the studies examined in this paper agree that each method that respects the rationality requirements and uses demonstrable information is generally acceptable. Therefore, the choice depends on the specific circumstances of the case which may require appropriate adjustments on crucial variables, such as discount rate and illiquidity discounts. In particular, several studies consider the methods based on rules of thumb also suitable for family businesses; whilst some consider them among the bluntest and indirect criteria for valuating a company, these methods are perhaps the most appropriate to obtain general values with an acceptable degree of significance in the field of family businesses.

The main limitation of the present study consists in the absence of a quantitative analysis due to the lack of empirical studies on the topic and the lack of FB databases.

It should be mentioned, among the points of strength of the present research, the fact that it is the first study, at least to our knowledge, that aims at organising and analysing the most relevant literature on the valuation of FBs during the evolution towards digitalisation.

The present paper lays the foundations of future research to investigate the digital growth/suitability of family businesses, along with the ambition of awakening those FBs that are still indecisive and have not yet dealt with digital transformation. The future area of research could be the development of a quantitative analysis that may highlight the input of intangible assets, intrinsic to the presence of the family members (business capabilities, experience, knowledge, and dedication of the owner and his/her members of the family), to the economic value of an FB that operates in an innovative and digital 
context. A comparison between the economic value generated by "traditional" and "digital" FBs may be further developed.

Author Contributions: Writing-original draft, O.F. and E.C. Both authors have read and agreed to the published version of the manuscript.

Funding: This research received no external funding.

Institutional Review Board Statement: Not applicable.

Informed Consent Statement: Not applicable.

Data Availability Statement: Not applicable.

Conflicts of Interest: The authors declare no conflict of interest.

\section{References}

Alcorn, Pat B. 1982. Success and Survival in the Family-Owned Business. New York: McGrawHill.

Amaduzzi, Andrea, Enrico Gonnella, and Giovanni Liberatore. 2016. I Principi di Valutazione d'Azienda. Esperienze Nord-Americane, Europee e Internazionali a Confronto. Milan: Giuffrè.

Ammirato, Salvatore, Francesco Sofo, Alberto M. Felicetti, Nina Helander, and Heli Aramo-Immonen. 2019. A new typology to characterize Italian digital entrepreneurs. The International Journal of Entrepreneurial Behaviour and Research 26: 224-45. [CrossRef]

Astrachan, Joseph H., and Melissa Carey Shanker. 2003. Family Businesses' Contribution to the U.S. Economy: A Closer Look. Family Business Review 16: 211-19. [CrossRef]

Ballwieser, Wolfgan. 2017. Valuation of family business. Paper presented at VI OIV International Business Valuation Conference, Business Valuation: A Pan-European Perspective, Milano, Italy, December 4.

Barnes, Louis B., and Simon A. Hershon. 1976. Transferring power in the family business. Harvard Business Review 54: 105-14.

Barry, Bernard. 1975. The Development of Organisation Structure in the Family Firm. Journal of General Management 3: 42-60. [CrossRef]

Bennedsen, Morten, Kasper M. Nielsen, Francisco Pérez-González, and Daniel Wolfenzon. 2007. Inside the family firm: The role of families in succession decisions and performance. The Quarterly Journal of Economics 122: 647-91. [CrossRef]

Blombäck, Anna, and Justin Craig. 2014. Marketing from a family business perspective. In The Sage Handbook of Family Business. Edited by Leif Melin, Mattias Nordqvist and Pramodita Sharma. London: London Sage, pp. 423-41.

Carsrud, Alan L. 1994. Meanderings of a Resurrected Psychologist or Lessons Learned. Creating a Family Business Program. Entrepreneurship Theory and Practice 19: 39-48. [CrossRef]

Cassandro, Paolo E. 1980. Sul concetto di economicità aziendale. Rivista Italiana di Ragioneria e di Economia Aziendale 5-6: 212.

CCEF. 2018. Taux D'Actualisation et Multiples de Valorisation. Parigi: CCEF.

Cecchetto, Andrea. 2019. La valutazione delle PMI dopo l'introduzione dei Piv: Spunti di riflessione. Rivista dei dottori Commercialisti 1: $11-24$.

Chua, Jess H., James J. Chrisman, and Pramodita Sharma. 1999. Defining the family business by behavior. Entrepreneurship Theory and Practice 23: 19-39. [CrossRef]

CNCC. 2016. L'evaluation Financière Expliqueée: Principes Et Démarches. In Département Édition. Parigi: CNCC.

CNDCE-FNC. 2020. Il Patto di Famiglia e il Passaggio Generazionale. Available online: https:/ / www.fondazionenazionalecommercialisti. it/node/1483 (accessed on 23 July 2020).

Conz, Elisa. 2020. Le Imprese Familiari nell'era del Marketing 4.0. Milano: EGEA.

Corbella, Silvano, Giovanni Liberatore, and Riccardo Tiscini. 2020. Manuale di Valutazione D'azienda. Milano: McGrawHill.

Corbetta, Guido, Alessandro Minichilli, and Fabio Quarato. 2020. Le Imprese Familiari Italiane di Fronte alla Pandemia Covid-19 Sintesi dei Risultati dell'Osservatorio AUB-XII Edizione. Edizione, Cattedra AidAF-Albert Falck di Strategia delle Aziende Familiari. Milano: Università Bocconi.

Corbetta, Guido, and Claudio Dematté. 1993. I Processi di Transizione nelle Imprese Familiari. Milano: Mediocredito Lombardo.

Daspit, Joshua J., James J. Chrisman, Triss Ashton, and Nicholas Evangelopoulos. 2021. Family Firm Heterogeneity: A Definition, Common Themes, Scholarly Progress, and Directions Forward. Family Business Review 25: 258-79. [CrossRef]

Davis, John A., and Rita M. Herrera. 1998. The social psychology of family shareholder dynamics. Family Business Review 11: 253-60. [CrossRef]

Davis, Peter. 1983. Realizing the potential of the family business. Organizational Dynamics 12: 47-56. [CrossRef]

Dell'Amore, Giordano. 1961. Le Fonti del Risparmio Familiare. Milano: Giuffrè.

Dell'Atti, Alberto. 2007. Il Passaggio Generazionale nelle Imprese Familiari. Bari: Cacucci Editore.

Deloitte. 2019. Global Family Business Report. Available online: https://www2.deloitte.com/it/it/pages/private/articles/globalfamily-business-survey-2019-cs---deloitte-italy---private.html (accessed on 20 June 2021).

Deloitte. 2020. Le Aziende Familiari di Prossima Generazione Report. Available online: https:/ /www2.deloitte.com/content/dam/ Deloitte/it/Documents/strategy/Next\%20Gen\%20Family\%20Study_Deloitte\%20Italia.PDF (accessed on 20 June 2021). 
Demirakos, Efthimios G., Norman C. Strong, and Martin Walker. 2004. What Valuation Models Do Analysts Use? Accounting Horizons 18: 221-40. [CrossRef]

Desmond, Glenn M. 1993. Handbook of Small Business Formulas and Rules of Thumb. Camden: Valuation Press.

Di Cagno, Nicola, Stefano Adamo, and Francesco Giaccari. 2011. Lineamenti di Economia Aziendale, 2nd ed. Bari: Cacucci.

Di Stefano, Giancarlo. 1996. La Compiuta Definizione Dell'azienda a Proprietà Familiare in AA.VV. L'azienda a Proprietà Familiare. Torino: Giappichelli.

Donnelly, Robert G. 1964. The Family Business. Harvard Business Review 42: 93-105. [CrossRef]

Dyer, Gibb W. 1986. Cultural Change in Family Firms. San Francisco: Jossey-Bass.

Dyer, Gibb W., Jr. 2003. The family: The missing variable in organizational research. Entrepreneurship Theory and Practice 27: 401-416. [CrossRef]

FEE. 2001. Business Valuation: A Guide for Small and Medium Sized Enterprises. Guide for Carrying Out Business Valuation. Available online: https: / www.accountancyeurope.eu/publications/business-valuation-a-guide-for-small-and-medium-sized-enterprises (accessed on 16 July 2001).

Ferrero, Giovanni. 1989. Impresa e Management. Milano: Giuffre.

Gersick, Kelin E., John A. Davis, Marion McCollom Hampton, and Ivan Lansberg. 1997. Generation to Generation, Life Cycles of the Family Business. Boston: Harvard Business Press.

Granata, Darya, and Francesco Chirico. 2010. Measures of Value in Acquisitions: Family Versus Nonfamily Firms. Family Business Review 23: 341-54. [CrossRef]

Guatri, Luigi, and Mario Bini. 2005. Nuovo Trattato Sulla Valutazione Delle Aziende. Milano: EGEA.

Habbershon, Timothy G., Mary Williams, and Ian C. MacMillan. 2003. A Unified systems perspective of family firm performance. Journal of Business Venturing 18: 451-65. [CrossRef]

Handler, Wendy. 1994. Entrepreneurship and Family Business: Exploring the Connections. Entrepreneurship Theory and Practice 19: 71-83. [CrossRef]

Hasso, Tim, and Keith Duncan. 2013. Valuation of Family Firms: The Limitations of Accounting Information. Australian Accounting Review 23: 135-50. [CrossRef]

Heck, Ramona K. Z., and Keith Stafford. 2001. The vital institution of family business: Economic benefits hidden in plain sight. In Destroying Myths and Creating Value in Family Business. Edited by G. K. McCan and N. Upton. Deland: Stetson University Press.

Hemerling, Jim, Julie Kilmann, Martin Danoesastro, Liza Stutts, and Cailin Ahern. 2018. It's Not a Digital Transformation without a Digital Culture. Boston Consulting Group. Available online: https:/ /www.bcg.com/publications/2018/not-digital-transformationwithout-digital-culture (accessed on 13 April 2018).

Hitchner, James R. 2012. Financial Valuation: Applications and Models, 3rd ed. Hoboken: John Wiley \& Sons.

IDW. 2014. IDW Application Guideline: Particularities of Determining the Objectified Business Value of Small and Medium-Sized Enterprises. Available online: https:/ / www.idw.de/the-idw/idw-pronouncements/idw-standards (accessed on 20 June 2021).

Lansberg, Ivan. 1988. The Succession Conspiracy. Family Business Review 1: 119-43. [CrossRef]

Le-Breton-Miller, Isabelle, Danny Miller, and Llyod P. Steier. 2004. Toward an integrative model of effective FOB succession. Entrepreneurship Theory and Practice 28: 305-28. [CrossRef]

Liberatore, Giovanni. 2012. La valutazione delle aziende di famiglia. In Aziende Famigliari e Longevità Economica. Modalità di Analisi e Strumenti Operativi. Edited by L. Del Bene, N. Lattanzi and G. Liberatore. Milano: IPSOA.

Marcello, Raffaele, and Matteo Pozzoli. 2019. Principi di valutazione aziendale. Variabili critiche nella valutazione delle piccole e medie imprese. Rivista dei Dottori Commercialisti 4: 671-84.

Marchini, Isa. 2000. Il Governo della Piccola Impresa. Le Basi delle Conoscenze. Urbino: Aspi/Ins, vol. I.

Morck, Randall, and Bernard Yeung. 2003. Agency problems in large family business groups. Entrepreneurship Theory and Practice 27: 367-82. [CrossRef]

Morris, Michael, Roy O. Williams, Jeffrey A. Allen, and Ramon A. Avila. 1997. Correlates of success in family business transitions. Journal of Business Venturing 12: 385-401. [CrossRef]

Mussolino, Donata. 2008. L'impresa Familiare. Padova: Cedam.

Mussolino, Donata, Amedeo Pugliese, and Riccardo Viganò. 2005. Ownership structure and business evaluation practices in family SMEs: Evidence from empirical research in Italy. Paper presented at Golden Opportunities for Entrepreneurship: Proceedings of 50th World Conference of International Conference of Small Business, Crystal Gateway Marriott, Washington, DC, USA, June 15-18. Available online: https:/ / eprints.qut.edu.au/38950/1/c38950.pdf (accessed on 20 June 2021).

Notarnicola, Giovanni, and Marco Carvelli. 2017. Gestire la trasformazione nell'era della digital transformation. Harvard Business Review 9: 60-68.

Onida, Pietro. 1971. Economia D'azienda. Milano: Utet.

Ordre Des Experts-Comptables. 2016. Mission d'évaluation-Guide Pratique. Parigi: Ordre Des Experts-Comptables.

Pasini, Paolo, and Angela Perego. 2016. Digitalizzare i Processi Aziendali. Milano: SDA Bocconi School of Management.

Picone, Pasquale M., Alfredo De Massis, and Yi Tang. 2021. The Psychological Foundations of Management in Family Firms: Values, Biases, and Heuristics. Family Business Review 34: 12-32. [CrossRef]

Ramírez, Rojo, García Domingo, and Pérez de Lema. 2005. Valoración de Pymes. In Document $n^{\circ} 7$ de Comisión de Valoración y Financiación de la Asociación Española de Contabilidad y Administración de Empresas. Madrid: AECA. 
Rogoff, Edward G., and Ramona K. Heck. 2003. Editorial: The evolving family/entrepreneurship relationship. Journal of Business Venturing 18: 559-688. [CrossRef]

Rondi, Emanuela, Alfredo De Massis, and Josip Kotlar. 2019. Unlocking innovation potential: A typology of family business innovation postures and the critical role of the family system. Journal of Family Business Strategy 10: 100315. [CrossRef]

Schillaci, Carmela E. 1990. I Processi di Transizione del Potere Imprenditoriale Nelle Imprese Familiari. Torino: Giappichelli.

Shanker, Melissa C., and Joseph H. Astrachan. 1996. Myths and realities: Family businesses' contribution to the US Economy-A framework for assessing family business statistics. Family Business Review 9: 107-23. [CrossRef]

Sharma, Pramodita, Carlo Salvato, and Trish Reay. 2014. Temporal Dimensions of Family Enterprise Research. Family Business Review 27: 10-19. [CrossRef]

Swab, Gabrielle R., Chelsea Sherlock, Erik Markin, and Clay Dibrell. 2020. "SEW" What do we know and where do we go? A review of socioemotional wealth and a way forward. Family Business Review 33: 424-45. [CrossRef]

Tagiuri, Renato, and John Davis. 1996. Bivalent attributes of the family firm. Family Business Review 9: 199-208. [CrossRef]

Tiscini, Riccardo. 2001. Il valore Economico Delle Aziende Di Famiglia. Dinamiche di Formazione e criteri di stima nelle aziende di Dimensione Minore. Milano: Giuffrè.

Viganò, Enrico. 2005. Il valore dell'impresa Nella Successione Familiare. Padova: Cedam.

Ward, James. 1987. Keeping the Family Business Healthy: How to Plan for Continuing Growth, Profitability and Family Leadership. San Francisco: Jossey-Bass.

Westhead, Paul, and Marc Cowling. 1998. Family Firm Research: The Need for a Methodological Rethink. Entrepreneurship Theory and Practice 23: 31-56. [CrossRef]

Wright, Mike. 1995. The family Business Survival Guide-Part 1. Best's Review 96: 82.

Zahra, Shaker A. 2003. International expansion of US manufacturing family businesses: The effect of ownership and involvement. Journal of Business Venturing 18: 495-512. [CrossRef]

Zahra, Shaker A., James C. Hayton, and Carlo Salvato. 2004. Entrepreneurship in Family vs. Non-Family Firms: A Resource-Based Analysis of the Effect of Organizational Culture. Entrepreneurship Theory and Practice 28: 363-81. [CrossRef]

Zappa, Gino. 1957. Le produzioni nell'economia Delle Imprese. Milano: Giuffré, vol. I. 